\title{
Altas Habilidades/Superdotação: políticas visíveis na educação dos invisíveis
}

\author{
High Skills/Giftedness: visible policies in invisible education
}

Altas Habilidades / Superdotación: políticas visibles en la educación de los invisibles

\section{Fanny Bianca Mette de Faveri}

Mestranda na Fundação Universidade Regional de Blumenau, Blumenau, Santa Catarina, Brasil. fannyfaveri@gmail.com

ORCID - https://orcid.org/0000-0003-1342-7014

\section{Marcia Regina Selpa Heinzle}

Professora doutora na Fundação Universidade Regional de Blumenau, Blumenau, Santa Catarina, Brasil. selpamarcia@gmail.com

ORCID - https://orcid.org/0000-0002-2299-8065

Recebido em 23 de julho 2018

Aprovado em 16 de outubro de 2019

Publicado em 12 de dezembro de 2019

\section{RESUMO}

Este artigo tem como objetivo apresentar aspectos históricos e conceituais das Altas Habilidades/Superdotação, relacionando-os com as políticas públicas existentes atualmente no Brasil. A partir dessa apresentação, busca-se estabelecer uma interface com os dados estatísticos referentes às matrículas na Educação Básica nos sistemas de ensino brasileiros. Como método, optou-se por uma pesquisa de análise documental por meio de estudos das legislações e políticas vigentes e do Censo Escolar (2013 a 2018). Para análise, buscamos teóricos e pesquisadores da área, como Renzulli; Reis (1986), Gama (2006), Pérez (2004, 2006, 2016), Sabatella (2008), Virgolim (2007, 2014), entre outros. O resultado aponta que o número de matrículas tem crescido, porém, ainda de forma lenta, pressupondo que há uma lacuna na identificação desses potenciais e um distanciamento entre o que está sendo realizado e o que é preconizado pela legislação educacional. Há a necessidade de uma constante reflexão e de estudos sobre políticas para Altas Habilidades/Superdotação, a fim de que sejam conhecidas e reconhecidas no campo educacional para fortalecer as ações.

Palavras-chave: Altas Habilidades/Superdotação; Políticas públicas; Censo escolar.

\section{ABSTRACT}

This article aims to present historical and conceptual aspects of the high skills / giftedness, relating them to the public educational policies that currently exist in Brazil. Based on this presentation, an attempt is made to establish an interface with the statistical data regarding enrollment in Basic Education in Brazilian education systems. As a method, documentary analysis was chosen together with studies of the current legislation and policies and the Brazilian school census (2013 to 2018). For analysis, we seek theorists 
http://dx.doi.org/10.5902/1984686X39198

and researchers of the area, such as Renzulli; Reis (1986), Gama (2006), Pérez (2004, 2006, 2016), Sabatella (2008), Virgolim (2007, 2014), among others. The result shows that the number of enrollments has increased, however, still slowly, assuming that there is a gap in the identification of these potentials and a gap between what is being achieved and what is recommended by the educational legislation. There is a need for constant reflection and studies on the policies for High Skills / Giftedness, so that they are known and recognized in the educational field, in order to strengthen the actions.

Keywords: High Skills/Giftedness; Public policy; School census.

\section{RESUMEN}

Este artículo tiene como objetivo presentar aspectos históricos y conceptuales de las Altas Habilidades / Superdotación, relacionándolos con las políticas públicas existentes actualmente en Brasil. A partir de esa presentación, se busca establecer una interfaz con los datos estadísticos referentes a las matrículas en la Educación Básica en los sistemas de enseñanza brasileños. Como método, se optó por una investigación de análisis documental por medio de estudios de las legislaciones y políticas vigentes y del Censo Escolar (2013 a 2018). Para el análisis, buscamos teóricos e investigadores del área, como Renzulli; Reis (1986), Gama (2006), Pérez (2004, 2006, 2016), Sabatella (2008), Virgolim (2007, 2014), entre otros. El resultado apunta que el número de matrículas ha crecido, pero aún de forma lenta, suponiendo que hay una laguna en la identificación de esos potenciales y un distanciamiento entre lo que se está realizando y lo que es preconizado por la legislación educativa. Hay necesidad de una constante reflexión y estudios sobre las políticas para Altas Habilidades / Superdotación, para que sean conocidas y reconocidas en el campo educativo, a fin de fortalecer las acciones.

Palabras clave: Altas Habilidades/Superdotación; Políticas públicas; Censo escolar.

\section{Introdução}

Apesar de não serem tão recentes, as políticas públicas para Altas Habilidades/Superdotação no Brasil ainda são pouco difundidas e conhecidas, mesmo no contexto educacional, mas elas existem e podem contribuir com informações para desmistificar o pensamento equivocado que se pode ter a respeito dessa temática. Havendo conhecimento, novas ações podem ser pensadas no intuito de contribuir na formação e na inclusão de estudantes com altas habilidades, que muitas vezes se tornam "invisíveis" aos olhos do sistema educacional.

Quando falamos em "educação dos invisíveis" referimo-nos aos muitos talentos que, por vezes, encontram-se perdidos nas escolas pela falta de conhecimento dos professores e do próprio sistema educacional, e, consequentemente, da não identificação a partir de avaliações mais precisas. Esse cenário aparece nos dados estatísticos do Censo Escolar ${ }^{1}$ (INEP, 2019), em forma de um percentual mínimo que não acompanha as estimativas para esta população. 
http://dx.doi.org/10.5902/1984686X39198

Sabemos que entender o fenômeno da superdotação não é tarefa fácil e depende de muito referencial teórico e embasamento na legislação. Este artigo tem como objetivo apresentar parte da trajetória das políticas para Altas Habilidades/Superdotação por meio de um histórico e de alguns contextos de influências americanas até chegar às ações realizadas no Brasil. Esta pesquisa também procura tratar da conceituação e da legislação vigente, tecendo uma reflexão a respeito das políticas públicas e de suas repercussões no cenário educacional.

A caracterização desta pesquisa sugere um cunho qualitativo por se apresentar dentro de características relevantes destacadas nesse tipo de abordagem, assim como nos sugerem Bogdan e Biklen (1994, p. 84), destacando que os investigadores qualitativos "partem para um estudo munidos dos seus conhecimentos e das suas experiências, com hipóteses formuladas com o único objetivo de serem modificadas e reformuladas à medida que vão avançando".

A pesquisa considerou os estudos de teóricos de Gama (2006), Pérez (2004, 2006, 2016), Renzulli; Reis (1986), Sabatella (2008), Virgolim (2007, 2014), entre outros. Para a análise documental das políticas públicas nacionais para Altas Habilidades/Superdotação foram analisados documentos públicos referentes às legislações nacionais. Utilizamos documentos oficiais como a Política Nacional de Educação Especial na Perspectiva da Educação Inclusiva (BRASIL, 2008), as Notas Técnicas oㅜ 11/2010 (BRASIL, 2010), nº 04/2014 (BRASIL, 2014) e ํㅜ 40/2015 (BRASIL, 2015), o Decreto ํ 7.611/2011 (BRASIL, 2011), o Plano Nacional de Educação - Lei 10.172/2001 (BRASIL, 2001a), além das Diretrizes Nacionais para a Educação Especial na Educação Básica - Parecer CNE/CEB 17/2001 (BRASIL, 2001b), dados do Censo Escolar dos anos de 2013 a 2018 (INEP, 2019), entre outros documentos norteadores das políticas para Altas Habilidades/Superdotação.

Este estudo se pautou em uma análise documental na qual Cellard (2008, p. 295) aponta que "o documento permite acrescentar a dimensão do tempo à compreensão do social". Ou seja, por meio do documento podemos ter acesso à coleta de informações distintas que possibilitam reflexões acerca dos procedimentos e ações demandados por uma política abrangente que tem o sujeito como base de suas práticas.

Nesse sentido, nos reportando às práticas educacionais no que tange ao atendimento de estudantes com Altas Habilidades/Superdotação, podemos entender que 
http://dx.doi.org/10.5902/1984686X39198

a ação política gera subsídios para o aprimoramento e a qualificação de um trabalho que pode ser constantemente adequado e estruturado conforme preconiza a legislação.

Para um melhor detalhamento e direcionamento das informações, este artigo foi dividido em cinco seções e organizado da seguinte forma: a) aspectos históricos da superdotação, na qual tecemos um breve panorama da trajetória dos estudos e atendimentos, bem como as influências na educação do Brasil; b) definições e teorias que regem as Altas Habilidades/Superdotação no Brasil, apresentando uma visão crescente a respeito das abordagens e conceitos, enaltecendo as contribuições de Joseph Renzulli (1986); c) contexto histórico das políticas públicas para Altas Habilidades/Superdotação no Brasil, na qual discutimos sobre os documentos oficiais; d) análise dos dados do Censo Escolar (INEP, 2019) em conformidade com a realidade vivenciada no país. Por fim, discutimos os resultados da pesquisa e fazemos nossas considerações finais.

\section{Aspectos históricos da superdotação: influências e Educação}

Quando nos reportamos aos estudos e ações sobre Altas Habilidades/Superdotação, havemos de considerar algumas influências que, possivelmente, os Estados Unidos trouxeram para a educação. Neste país, os estudos sobre a educação dos superdotados teve início no século XIX, quando as primeiras intenções de atendimento baseavam-se na capacidade intelectual e financeira dos estudantes que cursavam o ensino superior.

Em meados de 1866, houve o início do acompanhamento desses estudantes nas escolas públicas de Saint Louis, no estado do Missouri, e, em 1871, foi iniciado um sistema de promoção para a conclusão do ensino superior em menor tempo. De modo consequente, no ano de 1901, em Worcester, no estado de Massachusetts, foi criada a primeira escola especial para superdotados. Logo em seguida, no ano de 1905, os psicólogos franceses Alfred Binet e Théodore Simon iniciaram seus estudos nesta área e elaboraram escalas de avaliação, dando espaço para os primeiros testes de inteligência, em 1911.

Nesse sentido, Sabatella (2008) salienta que os testes de inteligência, desde aquela época, são realizados por meio de elementos que avaliam a memória, o raciocínio verbal, o raciocínio numérico, a análise de sequências lógicas e a habilidade de solucionar situações do cotidiano. 
http://dx.doi.org/10.5902/1984686X39198

Em 1912, Wilhelm Stern, psicólogo alemão, desenvolveu um cálculo matemático que posteriormente veio a se chamar Quociente de Inteligência (QI). Em 1916, o psicólogo Lewis Madison Terman adaptou os instrumentos juntamente com estudiosos americanos da Universidade de Stanford e estabeleceram novos padrões de escala, onde surgiu a chamada Escala de Inteligência Stanford-Binet. Houve evoluções no teste para modelos escritos e, a partir de 1920, a aplicação de testes com objetivos educacionais teve seu início nos Estados Unidos e na Europa. Todas essas descobertas contribuíram para a história da pesquisa e para os mecanismos de avaliação que até hoje são utilizados, porém com outros olhares para a identificação da inteligência, como sugere Gardner (1994).

Em se tratando de Educação, no ano de 1916, surgiram as primeiras classes específicas para alunos superdotados em Los Angeles, Califórnia, e em Cincinati, Ohio, depois, em 1922, em New York e Cleveland, Ohio. Nos anos 1950, começaram a ser reformados alguns currículos, surgindo novos programas e estratégias para o treinamento de professores com o objetivo de enfatizar a investigação do pensamento indutivo a partir de conteúdos referentes às estruturas das diferentes disciplinas curriculares. Nos apontamentos de Pérez (2004), em 1957, seria o momento no qual o governo norteamericano volta-se para as $\mathrm{PAHs}^{2}$, com o intuito de que essas pessoas viessem a ocupar as cadeiras de cientistas, matemáticos, físicos e pesquisadores.

Em 1970, algumas leis foram aprovadas nos Estados Unidos, dando maior e menor obrigatoriedade aos estados e à federação quanto à oferta de educação especial para estudantes superdotados (GAMA, 2006). Uma das ações mais importantes relativas à educação de superdotados foi a Javits Bill $(1987)^{3}$, criando o Centro Nacional de Pesquisa sobre Superdotados, estabelecendo verbas para projetos de treinamento e atendimento a esses alunos.

Segundo Gama (2006), atualmente, nos Estados Unidos, há uma diversidade no que diz respeito a programas de atendimento, incluindo programas de enriquecimento e aceleração nas escolas, salas de recursos, programas ligados às universidades, escolas para estudantes superdotados em diferentes áreas, programas de fim de semana, programas de férias, entre outros. Observando o cenário educacional relacionado às Altas Habilidades/Superdotação, hoje percebemos traços das influências referentes ao que se faz nos Estados Unidos. Os programas de atendimento que hoje existem na maioria dos países se deve, em grande parte, aos estudos e experiências oriundos de sua produção 
http://dx.doi.org/10.5902/1984686X39198

intelectual, sofrendo ajustes e especificações conforme cada legislação, porém, com foco mais educativo e educação especializada.

Alguns países da Europa também demonstraram interesse pela educação de superdotados, como a lugoslávia, a România, a Tchecoslováquia, a Espanha, a Polônia e a Holanda, onde os estudos e ações tiveram seu início, por exemplo, entre os anos de 1910, na lugoslávia, e 1936, na Espanha. Na Inglaterra, a partir dos anos 1960, os testes de aptidão e a educação diferenciada para os estudantes superdotados começaram a ser abolidos e nos anos 1980 surgiram, como opções, os programas de enriquecimento em sala de aula, o que representou um grande avanço para a educação nesse sentido.

No Canadá, as principais ações se baseavam no enriquecimento para a garantia da inclusão, parcerias entre educação regular e educação especial, educação individualizada e aprendizagem cooperativa. Desde o ano de 1969, algumas leis e regulamentações foram implantadas como parte da educação de alunos excepcionais.

No Brasil, o início dos estudos e atendimentos para estudantes com Altas Habilidades/Superdotação teve seu início no ano de 1929, por meio das primeiras pesquisas de Helena Antipoff (1892-1974), psicóloga e educadora russa. Com suas pesquisas, no ano de 1938, chamou a atenção para os estudantes que se destacavam por apresentarem habilidades superiores, os quais eram chamados de bem-dotados.

Seu trabalho teve início no ano de 1945 no Instituto Pestalozzi do Brasil, no Rio de Janeiro, mediante encontros com pequenos grupos de estudantes com potencial superior para estudar literatura, teatro e música. Os estudos de Antipoff foram de fundamental importância para que esses estudantes fossem vistos com outras perspectivas e possibilidades de acompanhamento. De acordo com Gama (2006), foi na Sociedade Pestalozzi que, em 1966, foram criados os primeiros seminários sobre Educação dos Superdotados.

As influências dos estudos de Antipoff e, posteriormente, dos programas de atendimento mais atuais e contemporâneos impactados pelos Estados Unidos, fortaleceram as ações para estudantes com altas habilidades no Brasil, que no decorrer dos anos foram conquistando mais espaço no cenário educacional.

\section{Definições, teorias e propostas que regem as Altas Habilidades /Superdotação no Brasil}

No decorrer dos anos, várias nomenclaturas foram utilizadas por diversos autores e estudiosos para conceituar Altas Habilidades/Superdotação. Porém, em conformidade 
http://dx.doi.org/10.5902/1984686X39198

com Pérez (2016), a variedade de termos e expressões tem gerado muitas confusões, tornando mais difícil a identificação e o registro desses estudantes no Censo Escolar e, consequentemente, a elaboração de políticas públicas eficientes, dificultando a construção de uma identidade sadia.

Ainda, segundo a autora:

[...] as confusões populares entre AH/SD e precocidade, genialidade, crianças prodígio e hiperatividade, que já têm sido bastante discutidas na literatura [...] a expressão AH/SD tem sido agraciada com diversas nomenclaturas, como altamente capaz, alto habilidoso, bem-dotado, brilhante, dotado, pessoa ou portador de altas habilidades, portador de genialidade, portador de superdotação, talentoso, superdotado [...] além dos tradicionais discriminatórios e preconceituosos Nerd e Geek, sabichão, CDF, entre outros. (PĖREZ, 2016, p. 46)

No Brasil, várias terminologias já foram utilizadas e algumas ainda persistem na nomeação de pessoas com Altas Habilidades/Superdotação. O termo Altas Habilidades foi adotado por influência do Conselho Europeu para Altas Habilidades - ECHA (European Council for High Ability); Superdotado ou Talentoso, adotado pelo conselho Mundial das crianças Superdotadas e Talentosas - WCGTC (World Council for Gifted and Talent Children) e Superdotação, utilizado pela Federação Ibero-Americana Ficomundyt (Federación Iberoamericana del World Council for Gifted and Talent Children) (SABATELLA, 2008).

A palavra "superdotado" foi usada, inicialmente, para "identificar indivíduos que se colocavam na faixa de $5 \%$ em relação à população, após um teste de inteligência geral" (SABATELLA 2008, p. 66). A Resolução CNE/CEB no 02/2001 (BRASIL, 2001b) traz, pela primeira vez, o termo "Altas Habilidades", porém, no ano conseguinte, o Conselho Brasileiro para Superdotação - ConBraSD, passa a reconhecer o termo "Altas Habilidades/Superdotação" como a nomenclatura mais apropriada a essa população, haja vista que trazia em sua essência um conceito mais abrangente.

Contudo, qual é o conceito que podemos definir a respeito das Altas Habilidades/Superdotação? Atualmente, o que temos como definição em termos de legislação? A Política Nacional de Educação Especial na Perspectiva da Educação Inclusiva (BRASIL, 2008, p. 15) estabelece que:

Estudantes com Altas Habilidades/Superdotação são aqueles que demonstram potencial elevado em qualquer uma das seguintes áreas, isoladas ou combinadas: intelectual, acadêmica, liderança, psicomotricidade e artes. Também apresentam elevada criatividade, grande envolvimento na aprendizagem e realização de tarefas em áreas de seu interesse. 
http://dx.doi.org/10.5902/1984686X39198

Apesar dessas especificações é importante destacar que uma pessoa com Altas Habilidades/Superdotação não manifesta seu comportamento apenas em uma área específica (linguística, lógico-matemática ou espacial), uma vez que são facilmente medidas em testes padronizados. Essas habilidades podem se estender para outras áreas do conhecimento humano, mas apenas a identificação por testes não supri os subsídios necessários para a verificação das habilidades por avaliar apenas o potencial intelectual por meio de provas de desempenho funcional. Dessa forma, como descrito por Virgolim (2014), é importante a utilização de métodos que possam identificar uma habilidade superior também em outras áreas como liderança, criatividade, competências psicomotoras e artísticas.

Em se tratando de testes, de acordo com Farias; Wechsler (2014), no Brasil existem vários deles que podem avaliar a inteligência, como a Escala Wechsler de Inteligência para Crianças (Wisc), a Bateria de Provas de Raciocínio (BPR-5), o Desenho da Figura humana (DFH-III), o Teste não Verbal de Inteligência para Crianças (R-2), o Teste Não Verbal de Inteligência (TNVRI), entre outros. Todos estes testes são aprovados pelo Conselho de Psicologia.

Interessante notar que ao falarmos em educação de estudantes com Altas Habilidades/Superdotação, a identificação apenas faz sentido quando é previsto algum tipo de atendimento educacional especializado. Levando em consideração esses aspectos, Gama (2006) menciona que a identificação com o único objetivo de rotular os alunos não presta qualquer serviço, uma vez que o rótulo provoca expectativas que a identificação por si só não pode satisfazer. Ainda segundo a autora, a identificação deve ser realizada como componente ou etapa de um sistema de planejamento de Programa Educacional Especial. Sendo assim, a identificação necessita estar em conformidade com os objetivos do programa (GAMA, 2006).

Para estudantes identificados com Altas Habilidades/Superdotação, a legislação prevê o Atendimento Educacional Especializado, ressaltando que todos os estudantes devem usufruir de um ambiente educacional enriquecedor, estimulante e criativo, que favoreça o seu desenvolvimento integral (BRASIL, 2015). A Nota Técnica no 40/2015/MEC/SECADI/DPEE define o atendimento educacional especializado da seguinte maneira:

Aos estudantes identificados com AH/SD, cabe à escola ofertar 0 atendimento educacional especializado - AEE. Para tais estudantes, o AEE caracteriza-se pela realização de um conjunto de atividades, visando 
http://dx.doi.org/10.5902/1984686X39198

atender as suas especificidades educacionais, por meio do enriquecimento curricular, de modo a promover a maximização do desenvolvimento de suas potencialidades e habilidades. A intervenção pedagógica deve oportunizar a manifestação da criatividade e originalidade; técnicas que cooperam com a elaboração de trabalho (s) na (s) área (s) de interesse; e atividades usadas para transformar os ambientes tornando-os mais adequados ao aprendizado. (BRASIL, 2015, n.p.).

Para tanto, o processo de identificação destes estudantes deve ter início em sala de aula, com o apoio do atendimento educacional especializado no intuito de localizar estes estudantes e oportunizar a realização de atividades que venham ao encontro com suas potencialidades por meio de propostas de enriquecimento em articulação com as ações da escola. Contudo, há ainda muitas lacunas nos aspectos que envolvem estes estudantes. Não obstante, no cenário da escola, a dificuldade se fixa desde o processo de identificação até o reconhecimento destes indivíduos como parte da Educação Especial.

O estudioso Joseph Renzulli (Renzulli; Reis, 1986) é considerado uma referência na atualidade quanto aos instrumentos e processos de identificação das características de indicadores de Altas Habilidades/Superdotação. O autor traz como concepção que a superdotação não é um conceito estático, senão dinâmico. Algumas pessoas podem apresentar um comportamento de superdotação em algumas situações de aprendizagem ou desempenho, mas não em todas elas.

Esta concepção se apresenta como uma das mais contemporâneas e geradoras de influência na avaliação de estudantes com Altas Habilidades/Superdotação. Essa nova forma de olhar a inteligência cedeu espaço para novas propostas de abordagens e avaliação, com um olhar mais amplo e transformador sobre a superdotação.

$\mathrm{Na}$ Teoria dos Três Anéis proposta por Renzulli (Renzulli; Reis, 1986) os comportamentos de superdotação estão relacionados a um grupo de três traços, desde que haja ligação entre si: capacidade acima da média, criatividade e comprometimento com a tarefa, podendo sofrer influências de fatores de personalidade e ambientais.

Figura 1 - Modelo Triádico de Superdotação

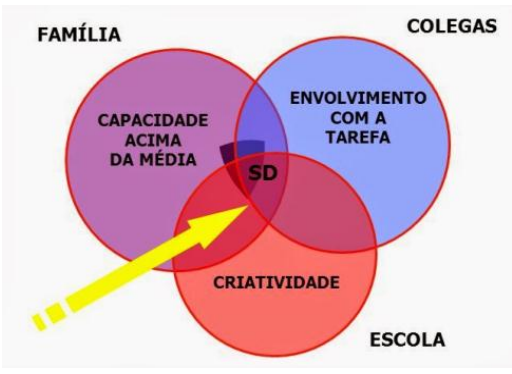

Fonte: Renzulli; Reis (1986). 
http://dx.doi.org/10.5902/1984686X39198

Na figura acima, a "capacidade acima da média" representa o domínio superior do potencial em alguma área, que pode ser geral, quando representa a grande capacidade de processamento de informação, ou específica, quando manifesta capacidade de adquirir conceitos, técnicas, práticas ou habilidades em uma área específica (VIRGOLIM 2014). O "envolvimento com a tarefa" enfatiza a parte motivacional e a energia direcionada na resolução dos problemas ou tarefas de forma perseverante, com dedicação, esforço e autoconfiança (VIRGOLIM, 2007). Já a "criatividade" diz respeito à originalidade e à utilidade, envolvendo aspectos relacionados à fluência, flexibilidade e originalidade de pensamento, curiosidade, sensibilidade e coragem de arriscar (VIRGOLIM, 2014). Vale ressaltar que essas três características não necessitam se manifestar com a mesma intensidade ou estar presentes ao mesmo tempo em todas as situações, porém a interação dos três traços proporciona a habilidade superior.

Estes conceitos apresentados pelo autor estão em consonância com o estabelecido pela Política Nacional de Educação Especial na Perspectiva da Educação Inclusiva (BRASIL, 2008), contribuindo para a concepção multidimensional de inteligência superior.

\section{As políticas públicas para Altas Habilidades/Superdotação no Brasil: o que dizem os documentos}

Há quem pense que as políticas públicas para Altas Habilidades/Superdotação são recentes e que, por este motivo, são pouco conhecidas e divulgadas, mas não é o que a história da educação brasileira nos mostra neste cenário. As primeiras intenções educacionais apresentam seus registros iniciais na década de 1930, com o início dos estudos referentes à superdotação, tendo como resultado algumas publicações na área. Apesar de não haver, à época, nenhuma legislação vigente, já havia o interesse em efetivar o trabalho e começar um novo ciclo.

Conforme Pérez (2004), o movimento em prol da inclusão no Brasil teve seu início em 1971, quando o Ministério da Educação começou a estabelecer os critérios para identificação e atendimento de alunos superdotados e logo depois promulgou a segunda Lei de Diretrizes e Bases da Educação Nacional (Lei 5.692/71). Esta lei trazia pela primeira vez o termo "superdotado" e, na ocasião, estabeleceu que os estudantes devessem receber tratamento especial de acordo com suas especificidades, sendo essas considerações um marco na história das Altas Habilidades/Superdotação. (BRASIL, 1971). Neste momento, os estudantes com superdotação saíram do grupo dos 
"excepcionais", termo utilizado na Lei de Diretrizes e Bases anterior - Lei 4.024/61 (BRASIL, 1961), e conquistaram nomenclatura própria.

A partir desse período, as propostas para atendimento e avaliação de alunos com Altas Habilidades/Superdotação foram sendo ampliadas e foram conquistando maior espaço, uma vez que, paulatinamente, novas legislações e políticas foram sendo criadas no intuito de fortalecer e de oferecer melhor atenção, assistência e educação adequada às necessidades desses estudantes.

Alguns pareceres e decretos foram criados posteriormente, reforçando a abordagem da Lei no 5.692/71, (BRASIL, 1971), oferecendo ações para implementação e algumas orientações a respeito da aprendizagem e matrícula de alunos superdotados. Isso reafirmou a integração na comunidade, reconhecendo-os dentro de suas particularidades, oferecendo a possibilidade de aceleração de estudos e a necessidade de capacitação dos profissionais.

O Núcleo de Apoio à Aprendizagem do Superdotado - NAS, criado no ano de 1975, chegou para atuar e contribuir com os atendimentos específicos para os estudantes com superdotação, porém, apenas para os estudantes do $1^{\circ}$ grau. No avanço dessa nova rede de apoio, surgiu a Associação Brasileira de Superdotação - ABSD, em 1979, que tinha como objetivo colaborar com as instituições públicas e particulares, realizar trocas de conhecimento e experiência entre indivíduos e instituições, promovendo encontros e seminários de pesquisa (GAMA, 2006).

Na década de 1980, foi criada a Secretaria de Educação Especial - SEESPE, que oferecia subsídios para a organização e funcionamento dos serviços especializados, atuando no desenvolvimento de programas, projetos e ações com o objetivo de implementar a Política Nacional de Educação Especial no país. A SEESPE lançou as Diretrizes Gerais para o Atendimento Educacional Especializado, as quais foram reeditadas, posteriormente, no ano de 1995. Mais tarde, no ano de 2011, esta secretaria foi extinta e seus programas foram vinculados à Secretaria de Educação Continuada, Alfabetização, Diversidade e Inclusão - SECADI.

Nesse primeiro ciclo de legislações para Altas Habilidades/Superdotação no Brasil, as ações se concentraram mais na busca pela estruturação e qualificação, principalmente, dos sistemas de ensino, no intuito de iniciar uma política baseada na inclusão e atendimento educacional. Entrando no segundo ciclo de políticas, podemos contar com uma visão um pouco mais centrada e voltada para as ações relacionadas ao 
http://dx.doi.org/10.5902/1984686X39198

processo de identificação e atendimento de estudantes com Altas Habilidades/Superdotação. Saíamos de um sistema mais fechado de ensino para um mais acessível, com estratégias e conceitos que seriam utilizados para qualificar e aos poucos introduzir uma estrutura mais eficaz de ensino e atendimento especializado.

O Plano Nacional de Educação compreendeu o decênio de 1993 a 2003, o qual orientou, em seu art. 26 (BRASIL, 2001a), a implantação gradativa de programas de atendimento aos alunos com altas habilidades nas áreas artística, intelectual ou psicomotora. O Plano buscava estimular as instituições de ensino superior a identificar, na educação básica, estudantes com altas habilidades intelectuais nos estratos de renda mais baixa, com vistas a oferecer bolsas de estudo e apoio ao prosseguimento dos estudos.

A primeira Política Nacional de Educação Especial foi criada no ano de 1994, com o objetivo de oferecer suporte legal e teórico para a Educação Especial, direcionando os trabalhos, definindo ações e clientela. É inegável o ganho que se teve com a Lei de Diretrizes e Bases da Educação Nacional (Lei no 9394/96), para os alunos com Altas Habilidades/Superdotação quanto ao reconhecimento de suas necessidades educacionais especiais, atendimento educacional especializado e aceleração de estudos para concluir em menor tempo os cursos realizados no âmbito da educação superior.

O Parecer CNE/CEB 17/2001, juntamente com a Resolução CNE/CEB № 2, de 11 de setembro de 2001, instituíram as Diretrizes Nacionais para a Educação Especial na Educação Básica. No que diz respeito à Resolução CNE/CEB no 2/2001, seu art. 8o estabelece que:

\footnotetext{
As escolas da rede regular de ensino devem prover na organização de suas classes comuns: [...] IX - atividades que favoreçam, ao aluno que apresente altas habilidades/superdotação, o aprofundamento e enriquecimento de aspectos curriculares, mediante desafios suplementares nas classes comuns, em sala de recursos ou em outros espaços definidos pelos sistemas de ensino, inclusive para conclusão, em menor tempo, da série ou etapa escolar, nos termos do Artigo 24, V, "c", da Lei 9.394/96. (BRASIL, 2001b, art. $8^{\circ}$ ).
}

O ano de 2003 foi marcado pela criação do Conselho Brasileiro para Superdotação (CONBRASD), em Brasília. O CONBRASD se trata de uma Organização Não Governamental (ONG), sem fins lucrativos, que visa a contribuir com a defesa dos direitos das pessoas com Altas Habilidades/Superdotação. Esta ONG busca estimular e incentivar a formação e o aperfeiçoamento de recursos humanos destinados à educação, à 
http://dx.doi.org/10.5902/1984686X39198

pesquisa, à identificação e ao atendimento de pessoas com altas habilidades e seus familiares (GAMA, 2006).

A partir do ano de 2005, os Núcleos de Atividades de Altas Habilidades/Superdotação (NAAH/S) foram criados em estados brasileiros e no Distrito Federal. As ações dos NAAH/S buscam coordenar a política de atendimento aos alunos com Altas Habilidades/Superdotação do sistema regular de ensino e propiciar a capacitação dos professores, propor parcerias com outras instituições governamentais e não governamentais a fim de atender as necessidades dos alunos e profissionais envolvidos, realizando um trabalho de assessoria, atendimento, identificação e orientação às famílias, escolas e estudantes.

Mais tarde, em 2008, foi instituída a Política Nacional de Educação Especial na Perspectiva da Educação Inclusiva, obtendo uma visão mais ampla e diagnóstica da Educação Especial, oferecendo subsídios para a implantação dos atendimentos e dos processos relacionados à demanda. Esta política aborda questões relacionadas à inclusão e atenta para as diferenças, orientando mudanças na estrutura da educação das pessoas com deficiência, transtornos globais do desenvolvimento e Altas Habilidades/Superdotação (BRASIL, 2008).

Nesta ocasião, o Brasil fechou este ciclo com a formação de uma política mais voltada para a inclusão e atendimento de estudantes, o público da Educação Especial. As legislações para Altas Habilidades/Superdotação começaram, a partir disso, a ter um pouco mais de abertura para desenvolver suas ações e a proporcionar mais oportunidades para se realizar um trabalho mais voltado para a prática, estabelecendo e proporcionando a criação de outros documentos norteadores do trabalho.

Após a implementação da nova política, a Resolução no 04, de 2 de outubro de 2009, (BRASIL, 2009), instituiu as Diretrizes Operacionais para o Atendimento Educacional Especializado na Educação Básica na modalidade Educação Especial. Posteriormente, a Nota Técnica no 11/2010/MEC/SEESP/GAB, de 07 de maio de 2010, surgiu para orientar quanto à institucionalização, na escola, da oferta do Atendimento Educacional Especializado - AEE, em Sala de Recursos Multifuncionais. Nas atribuições do professor de AEE (Atendimento Educacional Especializado) cabe desenvolver atividades de acordo com as necessidades educacionais dos alunos como a orientação de atividades de enriquecimento curricular para as Altas Habilidades/Superdotação (BRASIL, 2010). 
http://dx.doi.org/10.5902/1984686X39198

O Decreto $\mathrm{n}^{0}$ 7.611, de 17 de novembro de 2011, trouxe informações sobre a Educação Especial, mais especificamente sobre 0 Atendimento Educacional Especializado, dando outras providências. Dentre as ações, em seu art. $2^{\circ}$, inciso $1^{\circ}$, estabelece: "Il - suplementar a formação de estudantes com altas habilidades ou superdotação" (BRASIL, 2011).

A Lei no 10.172, de 9 de janeiro de 2001, aprovou o Plano Nacional de Educação e outras providências, entre elas, em seu art. 26, a implantação gradativa de programas de atendimento aos alunos com Altas Habilidades nas áreas artística, intelectual ou psicomotora (BRASIL, 2001a).

A Nota Técnica no 04/2014/MEC/SECADI/DPEE, de 23 de janeiro de 2014, trouxe orientações quanto a documentos comprobatórios do cadastro de alunos com deficiência, transtornos globais do desenvolvimento e Altas Habilidades/Superdotação no Censo Escolar. A Nota especifica que "não se pode considerar imprescindível a apresentação de laudo médico (diagnóstico clínico) por parte do aluno com deficiência, transtornos globais do desenvolvimento ou Altas Habilidades/Superdotação, uma vez que o AEE se caracteriza por atendimento pedagógico e não clínico" (BRASIL, 2014, n.p.). Nesses termos, fica claro que o sistema de avaliação é centrado em ações pedagógicas, evidenciado a função educacional do atendimento.

Já a Nota Técnica nº 40/2015/MEC/SECADI/DPEE, de 22 de abril de 2015, reforça aspectos ligados às Altas Habilidades/Superdotação, como atendimento, articulação do Projeto Político Pedagógico entre a escola e as instituições de ensino superior, parcerias com o NAAH/S e formação continuada dos professores (BRASIL, 2015).

Em se tratando de Educação Superior, a legislação não é tão específica a respeito das ações, porém, a Política Nacional de Educação Especial, na perspectiva da Educação Inclusiva (BRASIL, 2008), garante o atendimento educacional especializado em todos os níveis e modalidades de ensino.

Segundo Pérez (2006), a Educação Superior cumpre um importante papel no que diz respeito ao conhecimento científico referente às Altas Habilidades/Superdotação. A parceria destas instituições em questões relacionadas à identificação, atendimento, capacitação e formação de recursos humanos também é contemplada na legislação nacional.

Recentemente, no ano início do ano de 2019, houve a extinção da SECADI, dando espaço para o Decreto no 9.664, de 2 de janeiro de 2019, que institui à Diretoria de 
Acessibilidade, Mobilidade, Inclusão e Apoio às Pessoas com Deficiência, dentre outras ações, em seu art. 34, inciso V:

\begin{abstract}
Formular e implementar políticas para apoiar os sistemas de ensino na inclusão de estudantes com deficiência, transtornos globais do desenvolvimento e altas habilidades ou superdotação e favorecer o acesso, a permanência e a aprendizagem nas instituições educacionais em ambientes que maximizem seu desenvolvimento acadêmico e social. (BRASIL, 2019, art. 34, inciso V.)
\end{abstract}

Ao refletir sobre esta perspectiva e tendo em vista que os programas, desde a educação básica, devem ser garantidos em leis, a inclusão desse público deve ter a garantia de respeito ao seu potencial e a oferta de suplementação adequada.

Ao nos determos no contexto da educação básica, podemos mensurar que nas primeiras décadas de discussões acerca da Educação Especial, com foco voltado para as Altas Habilidades/Superdotação, houve um crescimento nas políticas públicas, resultando em ações que visavam beneficiar, através de práticas pedagógicas inclusivas, o desenvolvimento do potencial do estudante. O que vem se caracterizando, entretanto, é uma quebra nessas ações por meio das quais podemos inferir que, apesar das leis existirem e de haver um olhar para esse sujeito, de certa forma, ele pode permanecer desprovido de seus direitos, muitas vezes, pelo fato de não ser reconhecido. Ou seja, algumas ações são previstas pela legislação, mas há, certamente, uma lacuna na forma de identificação, tendo em vista que os números previstos não se efetivam no cenário educacional.

Contudo, se temos uma legislação que, apesar de tímida, mostra crescimento, por que o número de estudantes matriculados nas escolas e atendidos nos sistemas de Atendimento Educacional Especializado - AEE - ainda é tão baixo? A questão está em identificar esses estudantes "invisíveis" para que se sejam atendidos em suas especificidades. Mas de que forma? Vamos tratar disso a seguir fazendo um paralelo com os dados reais a partir dos documentos oficiais.

\title{
A "metade cheia do copo": contextos visíveis nas políticas para Altas Habilidades/Superdotação
}

Os movimentos relacionados a uma escola inclusiva que hoje se observam vêm caminhando em direção a uma perspectiva de muitas reformas e mudanças, porém, ainda observamos carências em algumas ações pedagógicas que possam suprir 
adequadamente as necessidades dos estudantes. É de fundamental importância que a escola esteja preparada e equipada para propiciar uma educação de qualidade, levando em conta qualquer tipo de diferença, não apenas a deficiência, mas também encorajando o desenvolvimento de talentos e de habilidades diversas.

Em se tratando de Altas Habilidades/Superdotação, geralmente, o cenário que se observa nas escolas é de um espaço de muitas dúvidas e inseguranças no que diz respeito às estratégias de ação e adaptações no currículo. Porém, antes de chegarmos nestas ações, há uma complexidade maior que merece ser discutida: o processo de identificação.

De acordo com Guenther (2016), a identificação na escola é um processo desenvolvido ao logo do tempo, com base na sequência dos acontecimentos reais, orientado por observação contínua, direta e sistemática, nas diversas situações de ação, produção e desempenho em que a criança está envolvida. Nessa perspectiva, Guenther (2016) reforça que a melhor maneira para que esta identificação aconteça seria localizar a capacidade natural do estudante, percebendo a sua maneira de aprender, responder e agir.

Entender o fenômeno das Altas Habilidades/Superdotação é complexo, bem como o seu processo de identificação. Entretanto, é necessário ressaltar a importância de esclarecer as informações para os principais envolvidos nesse processo: os professores. Nesse sentido, é preciso uma maior discussão para melhor conhecimento da temática, a fim de minimizar possíveis mitos e sensibilizar os docentes na busca de credibilidade de informações para possibilitar o reconhecimento de habilidades e talentos de estudantes dentro da escola, tornando-os visíveis.

Para entender que o número de estudantes identificados no sistema educacional brasileiro ainda se concentra em um número muito abaixo do que se é esperado, constituímos aqui uma interlocução entre os índices estimados e o percentual de estudantes cadastrados no Censo Escolar (INEP, 2019). É estimado pela Organização Mundial de Saúde que existam entre 5\% e $8 \%$ de pessoas com habilidades acima da média na população mundial (FARIAS; WECHSLER, 2014). Isso, considerando apenas os casos de superdotação acadêmica, sem contar com os outros tipos de habilidades como o Tipo Produtivo-Criativo, a qual contempla áreas do conhecimento como liderança, criatividade, competências psicomotoras e artísticas. Nesses casos, conforme Virgolim (2014), a estimativa aumenta de $15 \%$ a $20 \%$. 
http://dx.doi.org/10.5902/1984686X39198

Para melhor expor os dados referentes aos índices de estudantes com Altas Habilidades/Superdotação no Brasil, a tabela abaixo exibe um comparativo dos últimos seis anos, mediante dados obtidos pelo Censo Escolar de 2013 a 2018 (INEP, 2019). Estes dados estão relacionados apenas a estudantes matriculados na educação básica, não sendo computado o percentual de outras áreas ou demandas.

Tabela 1 - Cadastro de estudantes com Altas Habilidades/Superdotação no Censo Escolar.

\begin{tabular}{l|l}
\hline Ano do Censo Escolar & Números de estudantes no Brasil \\
\hline 2013 & 12.149 \\
2014 & 13.089 \\
2015 & 14.166 \\
2016 & 15.751 \\
2017 & 19.451 \\
2018 & 22.161 \\
\hline
\end{tabular}

Fonte: Elaborado pelas autoras, baseado no Censo Escolar 2013-2018 (INEP, 2019).

Os dados apresentam um aumento no número de matrículas, porém, mesmo com todo o aporte legal, o índice de alunos com Altas Habilidades/Superdotação identificados nas escolas ainda é pequeno. $O$ que acontece no cenário educacional é o fato das políticas, em sua maioria, serem pouco difundidas, conhecidas e compreendidas, evidenciando a falta de atenção a essa categoria que ainda convive com preconceitos e rejeições em sua vida escolar.

Ao nos pautarmos nos dados do Censo Escolar (INEP, 2019), veremos que os números nos mostram que o total de estudantes com Altas Habilidades/Superdotação cadastrados na educação básica apresenta um índice bem menor do que estima a Organização Mundial de Saúde, por exemplo, quando traça uma perspectiva do número de pessoas com altas habilidades. Podemos perceber que no período de um ano (2017 2018) houve um crescimento de apenas 2.710 estudantes cadastrados com Altas Habilidades/Superdotação a mais do que o ano anterior. Mesmo com o crescimento desta população, essa conta não fecha se tomarmos como base o número de matrículas realizadas na educação básica nesse último ano.

Os dados atualizados do Censo escolar de 2018 (INEP, 2019) nos informam que há um total de 48.455.867 estudantes matriculados na educação básica no Brasil. Se fizermos a conta de acordo com a estimativa da OMS, teríamos que obter, aproximadamente, um total de 2.422 .793 estudantes identificados nas escolas com Altas Habilidades/Superdotação. No entanto, os números atualizados do Censo de 2018 
http://dx.doi.org/10.5902/1984686X39198

também nos mostram que o número total de estudantes cadastrados é de apenas 22.161 (INEP, 2019).

Por outro lado, olhando a metade cheia do copo, nesse período de seis anos não podemos deixar de evidenciar que houve, de certa forma, um crescimento das matrículas em todos os anos, ainda que sutil. De 2013 a 2018, perfez-se um total de 10.012 estudantes identificados com Altas Habilidades/Superdotação a mais matriculados na Educação Básica. Desse percentual, o ano de maior número de matrículas foi o de 2017, com 3.700 estudantes a mais que o ano de 2016. Logo em seguida vem o ano de 2018, com 2.710 estudantes a mais que 2017.

Esses números nos mostram também, que as legislações e ações ofertadas para essa demanda vêm sendo efetivadas e que, apesar de tímidas, não tivemos números abaixo dos já computados nos anos anteriores. Contudo, há a necessidade de que essa caminhada seja mais incentivada e qualificada para se avançar cada vez mais nas propostas e, consequentemente, na realização de novas ações que possam vir a contribuir com a identificação e inclusão destes estudantes que, por vezes, permanecem no anonimato.

Brancher (2011) nos chama a atenção para a perspectiva que trabalhamos hoje com as Altas Habilidades/Superdotação, e considera que foi uma construção positiva que perpassou por inúmeros momentos formativos e constitutivos, até chegarmos ao momento em que temos como referência uma política mais consolidada.

Assim, é necessária uma constante reflexão sobre a importância que essas políticas representam para a educação, haja vista que é por meio delas que encontramos subsídios e amparos para a inclusão destes que ainda estão sem identificação nas escolas.

Nesse contexto, o conhecimento e o engajamento são o primeiro passo para que as políticas saiam do papel e adentrem a realidade educacional. As políticas existem e, desta forma, são visíveis. Elas estão disponíveis para quem as quer conhecer, explorar e refletir. As políticas são visíveis, sim, mas, por vezes, invisíveis aos olhos de quem não as quer enxergar. Invisíveis como as ações, as tentativas de inclusão e a aceitação. Invisível como a tolerância, a descrença e resistência em querer aprender para entender. Invisíveis são eles, os estudantes, que, por vezes, não são identificados e, assim, Ihes é tirado o direito de serem assistidos e compreendidos. 
http://dx.doi.org/10.5902/1984686X39198

As leis existem e são visíveis. Cabe haver mais discussões, envolvimento e estudos. $\mathrm{Na}$ atual realidade brasileira há uma dificuldade em identificar talentos na escola, uma vez que temos ainda uma grande lacuna no que diz respeito a esse processo. As escolas sentem-se perdidas e os professores desorientados, não sabendo como proceder e como ajudar a desenvolver as capacidades específicas dos estudantes. Mas, de fato, a identificação do estudante com Altas habilidades/Superdotação deve ter como finalidade o reconhecimento de talentos, buscando propostas de intervenção, promovendo melhores condições para o desenvolvimento desses sujeitos, respeitando as diferentes formas de aprender, pensar e agir.

\section{Considerações finais}

A legislação atual que rege a Educação Especial baseia-se na Política Nacional de Educação Especial na Perspectiva da Educação Inclusiva (BRASIL, 2008), que, por meio dos Decretos, Resoluções e Notas Técnicas, qualifica o trabalho e o acompanhamento dos estudantes com Altas Habilidades/Superdotação no país.

Com base nos documentos pesquisados, podemos dizer que o avanço das políticas públicas para Altas Habilidades/Superdotação apresentaram um crescimento mediante ações que visam beneficiar esse público através de práticas pedagógicas inclusivas e do desenvolvimento do potencial dos estudantes, porém, as políticas ainda são pouco conhecidas, comentadas, estudadas e difundidas, inibindo o crescimento das ações estabelecidas pelas legislações e o incentivo à pesquisa e atendimento dessa demanda.

Para que as ações previstas sejam realizadas e contempladas a estes estudantes, há a necessidade de haver maior discussão entre as esferas educacionais a fim de alavancar o trabalho e atingir um maior número de identificados para que saiam da invisibilidade. Só o conhecimento tem o poder de mudar um cenário que hoje ainda se encontra enfraquecido. Apesar dos índices mostrarem o quanto ainda temos que crescer, também não se pode deixar de prezar pelo que se tem evoluído até o momento. Cabe a todo o sistema educacional valorizar nossa legislação e trabalhar na efetivação de novas propostas.

Contudo, as legislações existem para dar um norte, indicar caminhos e orientar o trabalho, mas cabe aos atores que executam essas políticas, os professores, interpretálas e reconhecê-las como importantes para o processo de inclusão desses estudantes. A análise dos documentos oficias nos possibilita o conhecimento da legislação vigente e 
http://dx.doi.org/10.5902/1984686X39198

proporciona a discussão e, consequentemente, a implementação das ações previstas nas políticas públicas educacionais.

\section{Referências}

ANDRÉS, Aparecida. Consultoria Legislativa da Área XV. Educação, Cultura e Desporto. Educação de alunos superdotados/altas habilidades - Legislação e normas nacionais e Legislação internacional. Brasília, DF, 2010.

BRANCHER, Vantoir Roberto; FREITAS, Soraia Napoleão. (Orgs.). Altas

habilidades/superdotação: conversas e ensaios acadêmicos. Jundiaí: Paco, 2011.

BOGDAN, Robert; BIKLEN, Sari Knopp. Investigação qualitativa em Educação - uma introdução à teoria e aos métodos. Porto: Porto Editora, 1994.

BRASIL. Lei no 4.024, de 20 de dezembro de 1961. Fixa as diretrizes e bases da educação nacional. Lei de Diretrizes e Bases da Educação-LDB. Brasília, DF, 1961.

BRASIL. LEI no 5.692, de 11 de agosto de 1971. Fixa diretrizes e bases para o ensino de $1^{\circ}$ e $2^{\circ}$ graus, e dá outras providências. Lei de Diretrizes e Bases da Educação Nacional. Brasília, DF, 1971.

BRASIL. Ministério da Educação. Lei no 10.172, de 9 de janeiro de 2001. Aprova o Plano Nacional de Educação e dá outras providências. MEC/SECADI. Brasília, DF, 2001a.

Disponível em: http://www.planalto.gov.br/ccivil_03/leis/leis_2001//10172.htm. Acesso em: 11 jun. 2019.

BRASIL. Ministério da Educação. Diretrizes Nacionais para a Educação Especial na Educação Básica. Parecer CNE/CEB 17/2001. Brasília, DF: MEC, SEESP, 2001b. Disponível em: http://portal.mec.gov.br/seesp/arquivos/pdf/parecer17.pdf. Acesso em: 11 jun. 2019.

\section{BRASIL. Ministério da Educação. Política Nacional de Educação Especial na} Perspectiva da Educação Inclusiva. MEC/SEESP. Brasília, DF, 2008.

BRASIL. Ministério da Educação. RESOLUÇÃO № 4, DE 2 DE OUTUBRO DE 2009. Institui Diretrizes Operacionais para o Atendimento Educacional Especializado na Educação Básica, modalidade Educação Especial. Ministério da Educação. Conselho Nacional de Educação. Câmara de Educação Básica. Brasília, DF, 2009.

BRASIL. Ministério da Educação. Nota Técnica no 11, de 07 de maio de 2010. Orientações para a Institucionalização na Escola, da oferta de Atendimento Educacional Especializado - AEE em salas de recursos multifuncionais. MEC/SECADI/DPEE. Brasília, DF, 2010.

BRASIL. Ministério da Educação. Decreto no 7.611, de 17 de novembro de 2011. Dispõe sobre a Educação Especial, o atendimento educacional especializado e dá outras providências. MEC/SECADI. Brasília, DF, 2011. Disponível em: 
http://dx.doi.org/10.5902/1984686X39198

http://www.planalto.gov.br/ccivil_03/_ato2011-2014/2011/decreto/d7611.htm. Acesso em: 11 jun. 2019.

BRASIL. Ministério da Educação. Nota Técnica no 04, de 23 de janeiro de 2014.

Orientações quanto a documentos comprobatórios do cadastro de alunos com deficiência, transtornos globais do desenvolvimento e altas habilidades/superdotação no Censo Escolar. MEC/SECADI/DPEE. Brasília, DF, 2014.

BRASIL. Ministério da Educação. Nota Técnica no 40, de 15 de julho de 2015. O Atendimento Educacional Especializado aos Estudantes com Altas Habilidades/Superdotação. MEC/SECADI/DPEE. Brasília, DF, 2015.

BRASIL. Ministério da Educação. Decreto no 9.664, de 2 de janeiro de 2019. Brasília, DF, 2019. Disponível em: http://www.planalto.gov.br/ccivil_03/_ato20192022/2019/Decreto/D9665.htm. Acesso em: 12 jun. 2019.

CELLARD, André. A análise documental. In: POUPART, Jean; DESLAURIERS, JeanPierre; MAYER, Robert; GROULX, Lionel Henry; PIRES, Álvaro. A pesquisa qualitativa: enfoques epistemológicos e metodológicos. Petrópolis: Vozes, 2008. p. 295-316.

FARIAS, Eliana Santos de; WECHSLER, Solange Muglia. Desafios na identificação de alunos intelectualmente dotados. In: VIRGOLIM, Ângela Magda Rodrigues; KONKIEWITZ, Elisabete Castelon. (Orgs.). Altas habilidades/superdotação, inteligência e criatividade: uma visão multidisciplinar. Campinas: Papirus, 2014.

GAMA, Maria Clara Sodré S. Educação de superdotados: teoria e prática. São Paulo: EPU, 2006.

GARDNER, Howard. Estruturas da mente - a teoria das inteligências múltiplas. 1. ed. Porto Alegre: Artes Médicas, 1994.

GUENTHER, Zenita Cunha. Quem são os alunos dotados? Reconhecer dotação e talento na escola. In: MOREIRA, Laura Ceretta; STOLTZ, Tânia. (Coord.) Altas habilidades/superdotação, talento, dotação e educação. Curitiba: Juruá, 2016.

INEP - Instituto Nacional de Estudos e Pesquisas Educacionais Anísio Teixeira. Sinopse Estatística da Educação Básica 2013. Brasília: INEP, 2016. Disponível em: http://portal.inep.gov.br/censo-escolar-sinopse-sinopse. Acesso em: 21.set. 2018.

INEP - Instituto Nacional de Estudos e Pesquisas Educacionais Anísio Teixeira. Sinopse Estatística da Educação Básica 2014. Brasília: INEP, 2016. Disponível em: http://portal.inep.gov.br/basica-censo-escolar-sinopse-sinopse. Acesso em: 21 set. 2018.

INEP - Instituto Nacional de Estudos e Pesquisas Educacionais Anísio Teixeira. Sinopse Estatística da Educação Básica 2015. Brasília: INEP, 2016. Disponível em:

http://portal.inep.gov.br/basica-censo-escolar-sinopse-sinopse. Acesso em: 21 set. 2018.

INEP - Instituto Nacional de Estudos e Pesquisas Educacionais Anísio Teixeira. Sinopse Estatística da Educação Básica 2016. Brasília: INEP, 2017. Disponível em: 
http://dx.doi.org/10.5902/1984686X39198

http://portal.inep.gov.br/sinopses-estatisticas-da-educacao-basica. Acesso em: 30. set. 2018.

INEP - Instituto Nacional de Estudos e Pesquisas Educacionais Anísio Teixeira. Sinopse Estatística da Educação Básica 2018. Brasília: INEP, 2019. Disponível em:

http://portal.inep.gov.br/web/guest/sinopses-estatisticas-da-educacao-basica. Acesso em: 11 jun. 2019.

PÉREZ, Susana Graciela Pérez Barrera. Gasparzinho vai à escola: um estudo das características do aluno com altas habilidades produtivo-criativo. 2004. 307 f. Dissertação (Mestrado em Educação) - Faculdade de Educação, Pontifícia Universidade Católica do Rio Grande do Sul, Porto Alegre, 2004.

PÉREZ, Susana G. P. B. O atendimento educacional ao aluno com Altas Habilidades/Superdotação na legislação da Região Sul do Brasil: os lineamentos para concretizar uma quimera. In: FREITAS, Soraia Napoleão (Org). Educação e Altas Habilidades/Superdotação: a ousadia de rever conceitos e práticas. Santa Maria: UFSM, 2006.

PÉREZ, Susana Graciela Pérez Barrera. E que nome daremos à criança? In: MOREIRA, Laura C.; STOLTZ, Tânia. (coord.) Altas habilidades/superdotação, Talento, Dotação e Educação. Curitiba: Juruá, 2016.

RENZULLI, Joseph; REIS, Sally. The three-ring concepcion of giftedness: a devellopmental model for creative productivity. The triad reader. Connecticut: Creative Learning Press, 1986.

SABATELLA, Maria Lúcia Prado. Talento e superdotação: problema ou solução? 2. ed. Curitiba: Ibpex, 2008.

VIRGOLIM, Ângela Magda Rodrigues. Altas habilidades/superdotação: encorajando potenciais. Brasília (DF): Ministério de Educação, Secretaria de Educação Especial, 2007.

VIRGOLIM, Ângela Magda Rodrigues. A contribuição dos instrumentos de investigação de Joseph Renzulli para a identificação de estudantes com Altas Habilidades/Superdotação. Revista Educação Especial, v. 27, n. 50, set./dez. 2014. Disponível em: https://periodicos.ufsm.br/educacaoespecial/article/view/14281. Acesso em 10. jun. 2019.

\section{Notas finais}

${ }^{1}$ Os dados do Censo Escolar utilizados nesta pesquisa correspondem aos anos de 2013 a 2018.

2 Sigla utilizada para designar a expressão "Pessoas com Altas Habilidades/Superdotação". 
${ }^{3}$ A lei educacional Jacob Javits Gifted and Talented Students (Javits Act) foi aprovada pelo Congresso norte-americano em 1988 como parte da Lei de Ensino Fundamental e do Ensino Secundário (Elementary and Secondary Education Act) e destinou-se a apoiar o desenvolvimento de talentos nas escolas dos EUA. Seu objetivo era orquestrar um programa coordenado de pesquisa científica, projetos de demonstração, estratégias inovadoras e modelares e atividades similares para construir e reforçar a capacidade das escolas primárias e secundárias de satisfazer as necessidades educativas especiais dos alunos superdotados e talentosos. A lei direciona seus recursos na identificação e localização de estudantes subrepresentados nos programas de apoio a talentos (ANDRÉS, 2010).

\section{Correspondência}

Fanny Bianca Mette de Faveri - Fundação Universidade Regional de Blumenau, Rua Antônio da Veiga n. 140, Itoupava Seca, Blumenau, Santa Catarina - Brasil. CEP: 89030-903

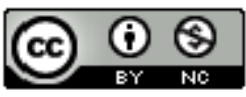

This work is licensed under a Creative Commons Attribution-NonCommercial 4.0 International (CC BY-NC 4.0) 